\title{
A New Caspase-8 Isoform Caspase-8s Increased Sensitivity to Apoptosis in Jurkat Cells
}

\author{
Zhifang Xu, ${ }^{1,2}$ Kejing Tang, ${ }^{1}$ Min Wang, ${ }^{1}$ Qing Rao, ${ }^{1}$ Bolin Liu, ${ }^{3}$ and Jianxiang Wang1 \\ ${ }^{1}$ State Key Laboratory of Experimental Hematology, Institute of Hematology and Blood Disease Hospital, \\ Chinese Academy of Medical Sciences and Peking Union Medical College, Tianjin 30020, China \\ ${ }^{2}$ Institute of Hematology, The Second Hospital of Shanxi Medical University, Taiyuan 030001, China \\ ${ }^{3}$ Department of Pathology, UCD-School of Medicine at Fitzsimons, Mail Stop 8104, P.O. Box 6511, \\ 12801 E. 17th Avenue Aurora, CO 80045, USA
}

Correspondence should be addressed to Jianxiang Wang, wangjx@ihcams.ac.cn

Received 15 July 2009; Revised 25 September 2009; Accepted 23 October 2009

Recommended by Phillip Bird

Caspase-8 is a key initiator of death receptor-induced apoptosis. Here we report a novel short isoform of caspase-8 (caspase-8s), which encodes the first (Death Effector Domain) DED and part of the second DED, missing the C-terminal caspase domain. In vivo binding assays showed that transfected caspase-8s bound to (Fas-associated death domain protein) FADD, the adaptor protein in (death-induced signal complex) DISC. To investigate the potential effects of caspase-8s on cell apoptosis, Jurkat cells were stably transfected with caspase-8s. Overexpression of caspase-8s increased sensitivity to the apoptotic stimuli, Fas-agonistic antibody $\mathrm{CH} 11$. These results suggest that caspase-8s may act as a promoter of apoptosis through binding to FADD and is involved in the regulation of apoptosis. In addition, the results also indicate that the first DED was an important structure mediating combination between caspase- 8 and FADD.

Copyright (C) 2009 Zhifang Xu et al. This is an open access article distributed under the Creative Commons Attribution License, which permits unrestricted use, distribution, and reproduction in any medium, provided the original work is properly cited.

\section{Introduction}

Apoptosis, or programmed cell death, is orchestrated by a family of proteases known as caspases that cleave their substrates after specific aspartic acid residues [1]. Caspases, including initiator caspases and effector caspases, are synthesized as catalytically inactive precursor proteins that become activated in response to specific death stimuli. The activation of initiator caspases such as caspase- $8,-10$, and -9 usually requires the assembly of the multicomponent complex DISC or apoptosome [2]. The processes have been described as two major pathways: extrinsic and intrinsic pathway. In the extrinsic pathway, apoptosis is mediated primarily by tumor necrosis factor (TNF) 1 family death receptors (DRs) such as CD95 or TRAIL receptors. Upon activation of the DR, the adaptor molecule FADD/Mort-1 is recruited to the receptors through its C-terminal death domain motif while it binds through its N-terminal DED to the two DED repeats in the N-terminal of caspase-8, forming DISC [3-5], and the resultant DISC will trigger the activation of procaspase-8. The functional caspase- 8 protease is then released into the cytosol, where it cleaves a number of cellular substrates such as effector caspases (caspase-3, -6, -7) initiating a caspase cascade and the subsequent apoptotic events. The active caspase- 8 also mediates the proteolytic cleavage of Bid into tBid, which is translocated to mitochondria and amplifies the intrinsic apoptosis pathway. Therefore, caspase- 8 plays a vital role in the propagation of enzymatic cascade that results in cell apoptosis [6-9].

To date, eight different isoforms, including Mcha1-3, Mchb1-4, and Mch5 (also designated as caspase-8/a-h) have been described at the mRNA level [10]. In this study, we found a new caspase- 8 isoform in acute leukemia (AL) and normal BMMNCs (bone marrow mononuclear cells), which encodes the first DED and part of the second DED, missing the C-terminal catalysis domain. Functional analysis indicated that the new isoform could bind to FADD and promote the apoptosis stimulated by Fas-agonistic antibody $\mathrm{CH} 11$ when stable transfected in Jurkat cells. In the caspase-8induced apoptosis pathway, the interaction between caspase8 and FADD is necessary for the formation of the DISC. But there is a controversy about the functions of the two DEDs 
of caspase- 8 in the interaction between caspase- 8 and FADD. The novel caspase-8s isoform we obtained only carries the first DED and a small part of the second DED, but it still can interact with FADD, indicating that the first but not the second DED represents a crucial element in interaction between caspase- 8 and FADD, and that the second DED is not a necessary domain for caspase- 8 to bind to FADD.

\section{Materials and Methods}

2.1. Acute Leukemia and Normal Samples. Bone marrow samples were obtained from patients with AL enrolled in the Institute of Hematology and Blood Disease Hospital, Chinese Academy of Medical Sciences. As control, bone marrow samples were obtained from healthy donors for hematopoietic stem cell transplantation as well. All samples were collected under informed consent of the subjects. BMMNCs were prepared by density gradient centrifugation over Ficoll solution (Invitrogen, USA) following the instructions of the manufacturer.

2.2. Cell Culture and Reagents. Human embryonic kidney 293T cells were cultured in Dulbecco modified Eagle medium (Life Technologies, USA). Human T-cell leukemia Jurkat cells were cultured in 1640 medium supplemented with $10 \%$ fetal calf serum at $37^{\circ} \mathrm{C}$ in a humidified environment of $5 \% \mathrm{CO}_{2}$. Anti-Fas (human, activating), clone $\mathrm{CH} 11$ (Upstate, CA), was used as apoptosis inducer.

2.3. RT-PCR Assays. Total RNA was extracted from $1 \times$ $10^{6}$ cells using Trizol (Invitrogen, USA) according to manufacturer's protocol. RNA concentration was determined by spectrophotometry at $260 \mathrm{~nm} / 280 \mathrm{~nm}$. OD260/OD280 $=1.8-2.0$ was taken as the range of pure RNA. cDNA was synthesized from $2 \mu \mathrm{g}$ RNA with Moloney murine leukemia virus reverse transcriptase (MMLV, Promega, USA) following the procedure provided by the manufacturer. PCR was performed to investigate the expression of caspase8 mRNA with the primers: sense primer $5^{\prime}$-AATGTTGGAGGAAAGCAATC- $3^{\prime}$ and antisense primer $5^{\prime}$-CATAGTCGTTGATTATCTTCAGC-3' ${ }^{\prime}$. PCR was carried out using Taq polymerase (Takara, Japan) and conducted as follows: $95^{\circ} \mathrm{C} 5$ minutes, 35 cycles of $95^{\circ} \mathrm{C} 30$ seconds, $55^{\circ} \mathrm{C}$ 30 seconds, $72^{\circ} \mathrm{C} 45 \mathrm{sec}$, and $72^{\circ} \mathrm{C} 8$ minutes. Primers spanning the whole CDS of caspase- 8 transcript are: sense primer $5^{\prime}$-CGGGATCCGCCATGGACTTCAGCAGAAATC- ${ }^{\prime}$ and antisense primer $5^{\prime}$-TCCCCCGGGCACCATCAATCAGAAGGG-3' . PCR was conducted as follows: $95^{\circ} \mathrm{C} 5$ minutes, 35 cycles of $95^{\circ} \mathrm{C} 30$ seconds, $55^{\circ} \mathrm{C} 1$ minute, $72^{\circ} \mathrm{C} 1$ minute, and $72^{\circ} \mathrm{C} 8$ minutes. The whole CDS region of FADD (GenBank accession no.NM_003824) was amplified with the sense primer 5' -GAATTCGACCCGTTCCTGGTGCT-3' and antisense primer $5^{\prime}$-CTCGAGAGTGCTGGGCTACCTTCC-3' under the following conditions: $95^{\circ} \mathrm{C} 5$ minutes, 35 cycles of $95^{\circ} \mathrm{C} 45$ seconds, $55^{\circ} \mathrm{C} 45$ seconds, $72^{\circ} \mathrm{C} 50$ seconds, and $72^{\circ} \mathrm{C} 8$ minutes. The PCR products of the CDS of caspase8 , caspase- $8 \mathrm{~s}$ and FADD were cloned into the pMD18-T vector (Takara, Japan) and sequenced by ABI PRISM 37796 genetic analyzer (Applied Biosystems, USA). The resulting plasmids were named pMD18-T-casp-8, pMD18-T-casp-8s and pMD18-T-FADD, respectively.

2.4. Western Blot Assays. Cell pellets were lysed in lysis buffer $(50 \mathrm{mM} \mathrm{KCl}, 2 \mathrm{mM} \mathrm{MgCl} 2,1 \mathrm{mM}$ EDTA, $5 \mathrm{mM}$ DTT, $25 \mathrm{mM}$ Tris (PH 7.5), $1 \mu \mathrm{g} / \mathrm{mL}$ leupeptin, $10 \mu \mathrm{g} / \mathrm{mL}$ aprotinin, and $1 \mathrm{mM}$ phenylmethylsulfonyl fluoride) on ice for 30 minutes and centrifuged for $5 \mathrm{~min}$ at $20,000 \mathrm{~g}$ at $4^{\circ} \mathrm{C}$. Protein concentration of the supernatant was determined using BCA protein assay reagents (Pierce, USA). The equal amounts of protein $(50 \mu \mathrm{g})$ were separated by $10 \%$ sodium dodecylsulfate-polyacrylamide gel electrophoresis (SDS-PAGE), electroblotted on nitrocellulose membranes, and immunostained with rabbit antiprocaspase-8 (C7849, Sigma) followed by horseradish peroxidase-conjugated antirabbit secondary antibodies (Jackson ImmunoResearch Laboratoriesm Inc, USA). Finally, the proteins were detected using enhanced chemiluminescence (Pierce, USA) according to the manufacturer's instructions.

2.5. In Vivo Protein Binding Assays. The pMD18-T-casp8 and pMD18-T-casp-8s were digested with restriction enzymes BamH I and EcoR I; the products containing only the two DEDs of caspase- 8 and caspase-8s were then cloned into the pcDNA 3.1 to construct the expression vectors pcDNA3.1-casp-8-2DED and pcDNA3.1-casp-8s2DED. The pMD18-T-FADD was digested with EcoR I and Xho I to construct pcDNA3.0-FADD. 293T cells were transiently transfected using calcium phosphate precipitation method and harvested after 48 hours, and then the cells were lysed and cleared by centrifugation. Rabbit anti-FADD (H$181 \mathrm{sc}-5559$, Santa Cruz) was added to the supernatant, and the cell lysate/antibody mixture was incubated overnight at $4^{\circ} \mathrm{C}$ on a rotator, then protein $\mathrm{A}$ or $\mathrm{G}$ agarose bead was added to the immunocomplex and incubated for another $1 \mathrm{~h}$ on a rotator, the immunoprecipitate was collected by centrifugation for 5 minutes at $20,000 \mathrm{~g}$ at $4^{\circ} \mathrm{C}$, the supernatant was discarded, and the beads were washed for 4 times with ice-cold PBS and resuspended in SDS-PAGE sample buffer and mixed gently and boiled for 5 minutes. Then western blot was performed with antiprocaspase- 8 as described above.

2.6. HIV-Based Lentivector Expression Vector Construction and Stable Transfection. A fragment encoding caspase-8s protein was amplified by PCR from pMD18-T-casp-8s vector. The sequences of the primers were devised as follows: forward 5'CCGGAATTCCGGATGGACTTCAGCAGAAAT$\mathrm{C}^{\prime}$, and reverse $5^{\prime}$ CGCGGATCCGCGATCTTCAGCAGGCTCTTG3'. The $414 \mathrm{bp}$ PCR product was inserted into pCDH1-MCS1-EF1-copGFP (SBI, USA), which was an HIVbased lentivector expression vector. A positive recombinant was identified by utilizing EcoR I/BamH I double digestion and direct sequencing. This construct and the other three packing plasmid mixture pPACKH1-GAG, pPACKH1-REV and, pVSV-G were transfected into $2.5 \times 10^{5} 293 \mathrm{~T}$ cells in 
six-well plate using calcium phosphate precipitation method. Viral supernatant was harvested after 48 hours and added to the $2 \times 10^{5}$ Jurkat cells at different dosages in 24-well plates. At 6 hours after infection, the culture medium was changed and followed by incubation at $37^{\circ} \mathrm{C}$ for 48 hours. As a control, a parallel vector without an insert was also performed. Both fluorescent microscopy and flow cytometric analysis of GFP were used to monitor lentivector infection of Jurkat cells. Individual clones with GFP expression were isolated by limited dilution, and stable cell lines containing pCDH1 empty vector and pCDH1-caspase-8s were established. Caspase-8s expression was confirmed by Western blot analyses.

2.7. Assessment of Cell Apoptosis and Viability. Empty vector or caspase-8s-transfected Jurkat cells and wild-type Jurkat cells were untreated or treated with monoclonal antihuman Fas antibody (clone $\mathrm{CH} 11$ ), and then the annexin VPE/7-AAD apoptosis detection kit (Pharmingen, San Diego, CA) was used to determine the frequency of apoptosis in cells according to the manufacturer's instructions. The cells were analyzed on the FACSscan. Early apoptotic cells were defined as those cells with Annexin $\mathrm{V}-\mathrm{PE}^{+} / 7-\mathrm{AAD}^{-}$ in the GFP expression positive cells. Apoptosis assays were run in triplicate. DNA ladder formation was analyzed by conventional electrophoresis. Approximately $2 \times 10^{6}$ cells were collected and washed twice with PBS. The pellet was incubated with lysis buffer (10 mM Tris- $\mathrm{HCl} \mathrm{pH}$ 8.0, $0.15 \mathrm{M}$ Nacl, 10 mM EDTA, 0.5\% sodium lauroylsarcosinate (SDS), $10 \mu \mathrm{M}$ proteinase $\mathrm{K}, 100 \mu \mathrm{M}$ RNase A) at $50^{\circ} \mathrm{C}$ for 2 hours. DNA was extracted by phenol and ethanol precipitation. After measuring the DNA concentration, an equal amount of DNA was examined on a $2 \%$ agarose gel stained with ethidium bromide (EB).

MTT assay was performed as previously described [11]. Briefly, $2 \times 10^{5}$ cells were plated in each well of 96-well microtiter plates with $100 \mu \mathrm{L}$ of fresh medium containing $\mathrm{CH} 11$ in various concentrations. After $24 \mathrm{~h}$ of further incubation, $20 \mu \mathrm{L}$ of MTT solution $(2.5 \mathrm{mg} / \mathrm{mL})$ was added to each well and the cells were further incubated for $4 \mathrm{~h}$. The medium was then removed and the formed formazan crystals were dissolved in $150 \mu \mathrm{L}$ of dimethyl sulfoxide (Sigma, USA). The plates were placed on a plate shaker for $10 \mathrm{~min}$ and the absorbance of the resulting solution was immediately measured at $546 \mathrm{~nm}$ using a microplate reader (SLT-Lab, Salzburg, Austria). Inhibition ratio was calculated with the formula: inhibitory rate $=(1-\mathrm{T} / \mathrm{C}) \times 100 \%$ where $\mathrm{T}$ is the absorbance rate of treatment group with $\mathrm{CH} 11$ and $\mathrm{C}$ is the absorbance rate of control group. These experiments were repeated three times.

2.8. Assessment of Mitochondrial Membrane Potential. Mitochondrial membrane potential was measured using DiOC6/PI test. $5 \times 10^{5}$ cells were washed in PBS and incubated at $37^{\circ} \mathrm{C}$ for $30 \mathrm{~min}$ with $40 \mathrm{nM} \mathrm{3,3}$ dihexyloxacarbocyanine (DiOC6, Sigma aldrich) in combination with $5 \mathrm{mg} / \mathrm{mL}$ propidium iodide (PI, Sigma). The fluorescence was measured by flow cytometry.
2.9. Detection of Fas Expression by Semiquantitative RTPCR and Flow Cytometric Analysis. Total RNA was extracted from wild-type Jurkat cells, empty vector, and caspase8s-transfected Jurkat cells; then RT-PCR was performed with the sense primer $5^{\prime}$-CAAGGGATTGGAATTGAGGA$3^{\prime}$ and antisense primer $5^{\prime}$-GACAAAGCCACCCCAAGTTA$3^{\prime}$ under the following conditions: $94^{\circ} \mathrm{C} 5 \mathrm{~min}, 28$ cycles of $94^{\circ} \mathrm{C} 45 \mathrm{sec}, 58^{\circ} \mathrm{C} 50 \mathrm{sec}, 72^{\circ} \mathrm{C} 50 \mathrm{sec}$, and $72^{\circ} \mathrm{C} 8 \mathrm{~min}$ [12]. Each reverse-transcribed mRNA product was internally controlled by GADPH. Cell surface Fas antigen, were quantified as follows: cells $\left(5 \times 10^{5}\right.$ cells/sample $)$ were collected and washed with PBS and then were incubated with PE anti-human Fas (CD95) monoclonal Ab (DX2, Biolegend, San Diego, CA) or PE-conjugated mouse IgG1 (Pharmingen) as a isotype negative control at room temperature for $30 \mathrm{~min}$. After two washes with PBS, the cells were analyzed for surface Fas expression by flow cytometry.

\section{Results and Discussion}

3.1. Identification of a Novel Isoform of Caspase-8 (Caspase8 s). The human caspase- 8 gene encodes an interleukin- $1 \mathrm{~b}$ converting enzyme-(ICE-) related cysteine protease. It was reported that the caspase- 8 gene contains at least 11 exons on human chromosome band 2q33-34, a region where loss of heterogeneity ( $\mathrm{LOH}$ ) has been found in a number of tumors [13]. In a panel of human cancer and cell lines, mutations of caspase- 8 gene have also been reported [1417]. Recent studies showed that the hypermethylation of the caspase- 8 gene promoter region and subsequent lack of caspase-8 expression is related to some tumor cells [18-21]. All these researches suggested that abnormalities of caspase8 gene may be correlated with tumors. In our study, reverse transcriptase-polymerase chain reaction (RT-PCR) was performed to investigate the expression of caspase- 8 mRNA in BMMNCs derived from AL patients. To our surprise, a shorter amplified product was visible in addition to the wild type product of caspase-8 (Figure 1(a)). By sequencing, a $106 \mathrm{bp}$ deletion was identified compared to the released caspase-8 database (GenBank accession no.NM_033355). Subsequently, the entire CDS (coding sequence region) of this short caspase- 8 transcript as well as the part of untranslated region (UTR) was amplified and sequenced, and no other mutations were found in addition to the $106 \mathrm{bp}$ deletion. The new caspase- 8 transcript was also expressed in BMMNCs from healthy individuals and was named as caspase-8s (caspase-8 short form, GenBank accession no. EU670044). We next examined whether caspase-8s transcript is also expressed in cell lines. RT-PCR detected transcripts representing caspase- 8 as well as caspase- $8 \mathrm{~s}$ in most cell lines. RT-PCR also revealed that the ratio of caspase- 8 to caspase$8 \mathrm{~s}$ varied in different cell lines, but the expression level of caspase- 8 mRNA was higher than that of caspase- $8 \mathrm{~s}$ in all the cell lines (Figure 1(b)).

Analyses of nucleotide and deduced amino acid sequences revealed that the $106 \mathrm{bp}$ deletion resulted in a frameshift mutation carrying a stop codon and termination of the transcript in advance, with the predicted generation 


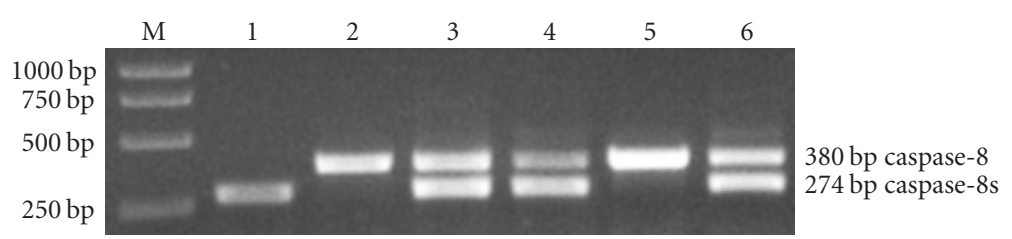

(a)
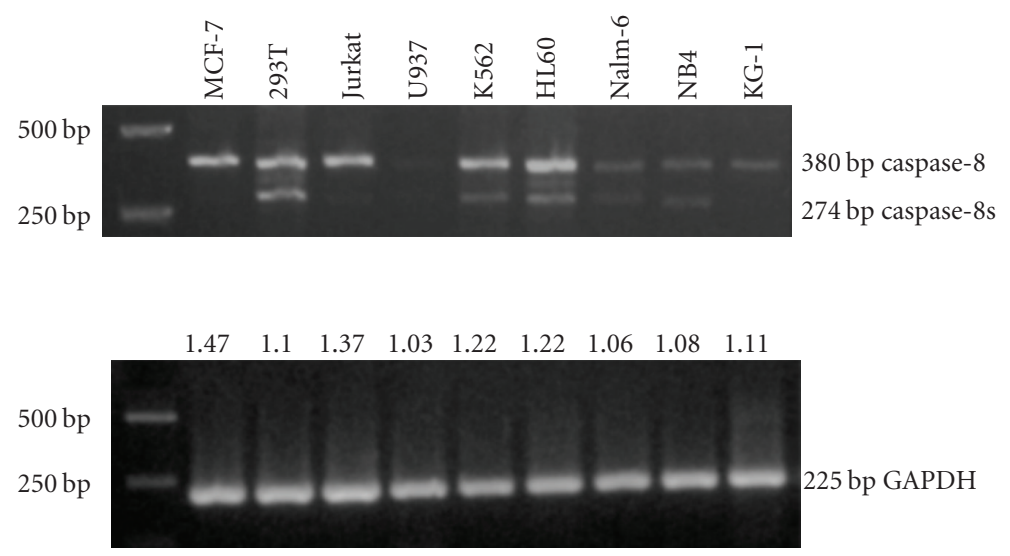

(b)

FIGURE 1: (a) Identification of a novel isoform of caspase-8 (caspase-8s): RT-PCR analysis of mRNA expression of caspase-8s from the bone marrow cells of AL individual. The PCR products were separated on $1.5 \%$ agarose gel and visualized by ethidium bromide staining. In addition to the expected bands $(380 \mathrm{bp}$ ) representing wild type caspase- 8 , a small amplicon representing caspase-8s was identified (274 bp). (b) Coexpression of caspase-8 and caspase-8s in various cell lines: RT-PCR was carried out with RNA isolated from various cell lines as described under "Materials and Methods." The PCR products were resolved on 1.5\% agarose gel and visualized by ethidium bromide staining. GAPDH was used as a loading control. $\mathrm{R}$ = densitometrical units of caspase-8/densitometrical units of GAPDH.

of a 108aa protein, as compared with the 479 aa of caspase- 8 (GenBank accession no.AAD24962). The molecular mass of the predicted protein was estimated to be $13 \mathrm{KD}$. The complementary DNA (cDNA) and protein sequences of which were shown in Figure 2. By Western blot assays, we detected the caspase-8s protein product existed in some but not all leukemia samples. Some acute leukemia patient examples of the Western blots are shown in Figure 3.

For caspase-8, eight different isoforms, including Mcha1-3, Mchb1-4, and Mch5, have been described at the mRNA level [10]. Mcha1, Mcha2, and Mch5 are the three procaspase- 8 isoforms, all of which possess a long N-terminal prodomain harboring two highly homologous DEDs, DED1 (1-75aa) and DED2 (99-176aa), followed by a C-terminal protease domain that can be divided into two subunits, p18 and p11. mRNA of these three procaspase- 8 isoforms are expressed in a wide variety of tissues, with the highest expression in peripheral blood leukocytes, spleen, thymus, and liver but barely detectable expression in brain, testis, and skeletal muscle. But only two of them, Mcha1 and Mcha2, were detected at the protein level of all cell lines tested. Both isoforms were recruited and activated by the DISC with identical kinetics [22]. Other isoforms, Mcha3 that lacks DED, and Mchb1-4 that lacks catalytic domain, are supposed to modulate the activity of caspase- 8 . Caspase$8 \mathrm{~L}$ is a recently reported novel isoform of caspase- 8 , which was generated by alternative splicing of intron 8 , carrying a $136 \mathrm{bp}$ insertion and frame shift of the transcript. The transcript misses the catalytic site of caspase- 8 but retains the DEDs. Functional assays indicated that caspase-8L acted as an inhibitor of caspase- 8 by interfering with the binding of caspase- 8 to FADD and was involved in the regulation of Fas-mediated apoptosis [23]. Kisenge et al. [24] also confirmed the existence of a caspase- 8 variant in some neuroblastoma cell lines, which was impaired in the first DED and showed moderate sensitivity to Fas-mediated cell death. In our study, the new caspase-8s isoform only carries the first DED (75 aa) and part of the second DED (7aa), which is not reported in the published literature.

3.2. Caspase-8s as well as Caspase-8 Binds to FADD. In the caspase-8-induced apoptosis pathway, the interaction between caspase- 8 and FADD is necessary for the formation of the DISC. To determine whether caspase- $8 \mathrm{~s}$ can bind to FADD through its incomplete DEDs and whether "two" intact tandemly repeated DEDs are necessary for interacting between caspase- 8 and FADD, we performed in vivo binding and co-immunoprecipitation assays; the results demonstrated the specific binding of FADD to caspase$8 \mathrm{~s}$ as well as to caspase- 8 (Figure 4 ). The apoptotic signal from ligand-induced oligomerization of death receptors is mediated by a complex of proteins containing specialized interaction domains. This complex consists of the death domain (DD), the caspase recruitment domain (CARD), and the DED. The DED was first described in the FADD/Mort1 protein and later shown to also occur in several other 


\begin{abstract}
241 atggtgccag gaaagggtgg agcggattat attctcctgc cttttaaaaa gatggacttc
301 agcagaaatc tttatgatat tggggaacaa ctggacagtg aagatctggc ctccctcaag

361 ttcctgagcc tggactacat tccgcaaagg aagcaagaac ccatcaagga tgccttgatg

421 ttattccaga gactccagga aaagagaatg ttggaggaaa gcaatctgtc cttcctgaag

481 gagctgctct tccgaattaa tagactggat ttgctgatta cetacctaaa cactagaaag

541 gaggagatgg aaagggaact tcagacacca ggcagggctc aaatttctgc ctacagggtc

601 atgctctatc agattcaga agaagtgagc agatcagaat tgaggtcttt taagtttctt
\end{abstract}

661 ttgcaagagg aaatctccaa atgcaaactg gatgatgaca tgaacctgct ggatatttc

721 atagagatgg agaagagggt catcctggga gaaggaaagt tggacatcct gaaaagagtc

781 tgtgcccaaa tcaacaagag cetgctgaag ataatcaacg actatgaaga attcagcaaa

(a)

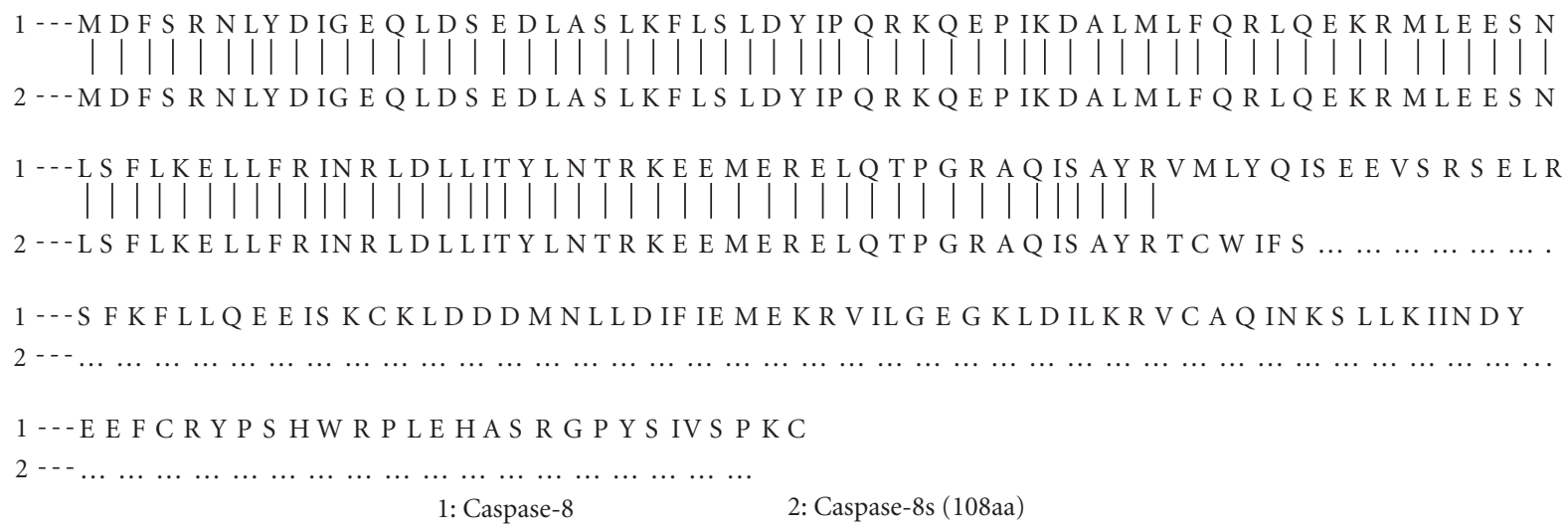

(b)
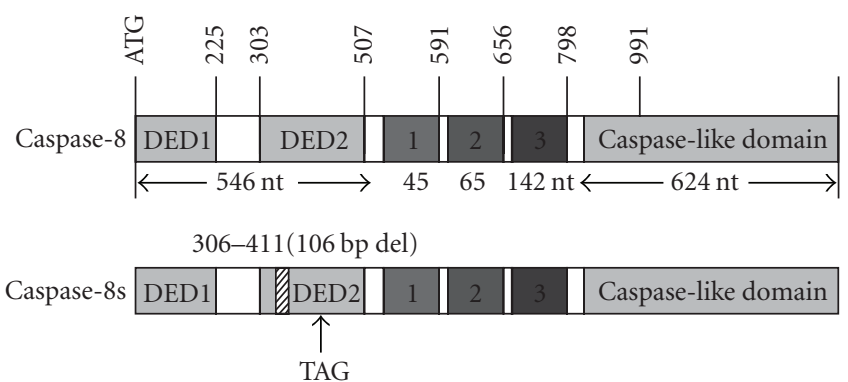

(c)

FIGURE 2: The cDNA and protein sequences of the novel isoform of caspase-8 (caspase-8s). (a) The sequence from start codon ATG to stop codon TAG of caspase-8s comparing with caspase-8. the sequence underlined is the deletion region. (b) The protein sequence of caspase8 and caspase-8s. (c) Scheme illustrates that the deletion may result in the termination of the transcript in advance with the predicted generation of 108 aa protein.

proteins [25-29]. Caspase-8 protein has two DEDs, which are essential for the binding between the caspase- 8 prodomain and FADD by yeast two-hybrid experiments $[4,5]$. Previous studies using deletion and chimeric mutants of caspase- 8 DEDs demonstrated that the two domains are necessary for caspase- 8 to function normally, and when one domain was deleted, function of the resulting mutant protein decreased to about half that of normal caspase-8 [30]. Liu et al. [17] reported a novel caspase- 8 mutant with a naturally occurring deletion of leucine 62 in the first DED, which failed to interact with FADD and lost proapoptotic activity. Carrington et al. [31] identified a procaspase-specific binding surface on the DED of FADD, suggesting a preferential interaction with one, but not both, of the DEDs of procaspase- 8 in a perpendicular arrangement. All these showed that there is a controversy about the functions of the two DEDs. The novel caspase-8s isoform we obtained only carries the first DED and a small part of the second DED, but it still can interact 


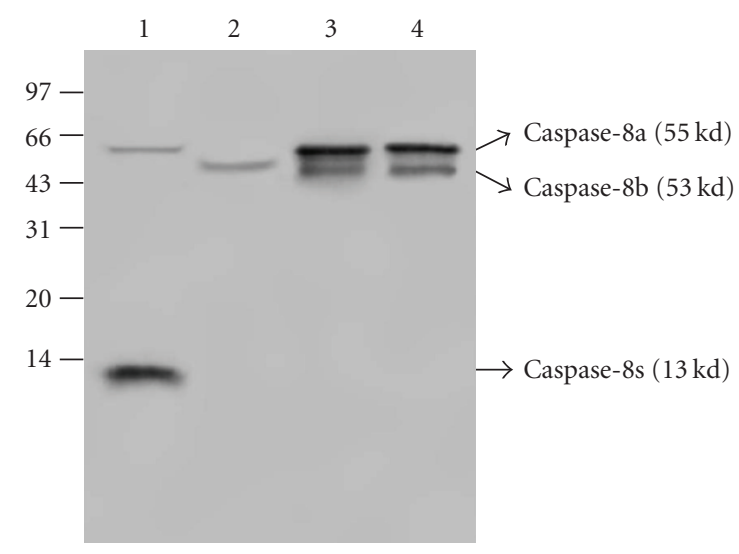

FIGURE 3: SDS-PAGE analysis of caspase-8s protein expression in human AL bone marrow cells: lane 1-4: acute leukemia patient samples; $50 \mu \mathrm{g}$ of total protein from lysates of human AL bone marrow cells were subjected to $10 \%$ SDS-PAGE and immunoblotted with the rabbit antiprocaspase- 8 corresponding to the N-terminal of human caspase- 8 prodomain (C7849, Sigma). In addition to the two expected bands $(55 \mathrm{kd}$ or $53 \mathrm{kd}$ ) representing wild type caspase-8a/b, a small band (13 kd) representing caspase-8s was identified in lane 1.

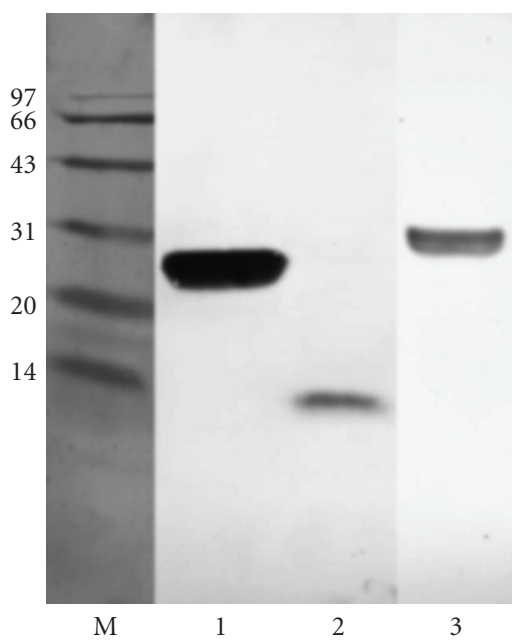

(a)

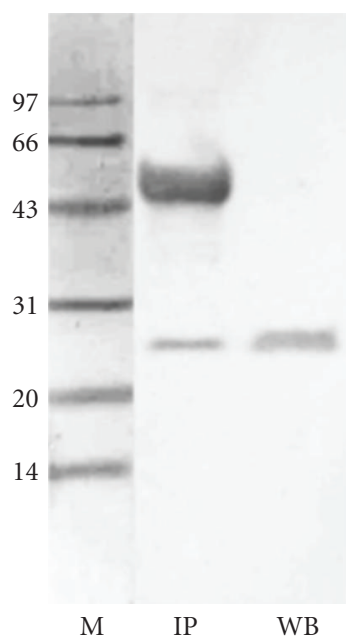

(b)

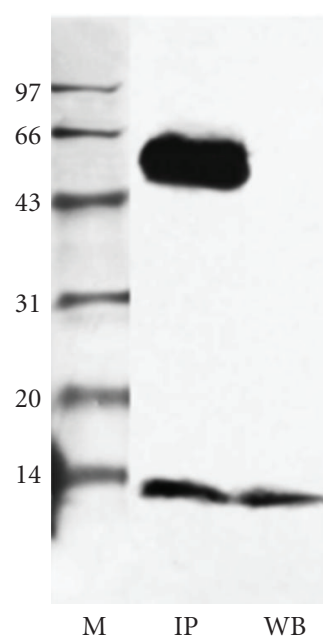

(c)

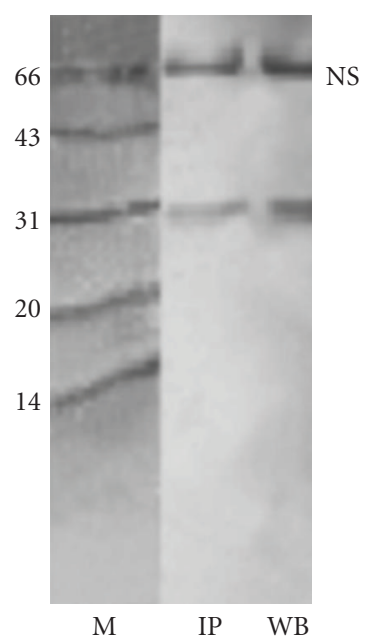

(d)

FIgURE 4: Interaction of the caspase-8s-2DED and FADD. (a) Western blot analysis of the expression of cellular extracts from 293T cells transfected with expression constructs encoding caspase-8-2DED (24 kd, lane 1), caspase-8s-2DED (13 kd, lane 2), and FADD (28 kd, lane 3 ) by antiprocaspase- 8 and anti-FADD antibodies, respectively. (b) 293T cells were cotransfected with expression constructs for human FADD and caspase-8-2DED, lysed and immunoprecipitated (IP) with anti-FADD polyclonal antibody and immunoblotted with antiprocaspase-8. The upper band in IP lane is rabbit IG heavy chain. $50 \mu \mathrm{g}$ total cell lysate was loaded as control (WB). (c) 293T cells were cotransfected with expression constructs for human FADD and caspase-8s-2DED, and the co-immunoprecipitation assay was done as (b). (d) 293T cells were cotransfected with expression constructs for human FADD and caspase-8s-2DED, lysed and immunoprecipitated (IP) with antiprocaspase-8 and immunoblotted with anti-FADD polyclonal antibody. NS indicates the unspecified bands; $50 \mu \mathrm{g}$ total cell lysate was loaded as control (WB).

with FADD, indicating that the first but not the second DED represents a crucial element in interaction between caspase8 and FADD, and that the second DED is not a necessary domain for caspase- 8 to bind to FADD.

\subsection{Overexpression of Caspase-8s Increased Sensitivity to} Apoptosis in Jurkat Cells. The ability of caspase-8s to integrate with FADD in vivo suggests that it might be involved in apoptosis pathway. To test this possibility, we stably transfected Jurkat cells with a lentivector expression vector construct encoding caspase-8s. The Jurkat cell line was chosen by two reasons: first, caspase- 8 s expression was detected to be lower than caspase- 8 expression in this cell line; second, the cell line was sensitive to apoptosis stimuli such as anti-Fas antibody. Individual clones with green fluorescent protein (GFP) expression were isolated by limited dilution and successful expression of caspase-8s constructs was confirmed by Western blot analysis (Figure 5). Western blot revealed that wild type Jurkat cells and pCDH-empty vector-Jurkat cell clone JP4 did not express caspase-8s protein and that the pCDH-caspase- 8 s-Jurkat cell clones JS2 and JS3 expressed caspase-8s protein, and that they all expressed 


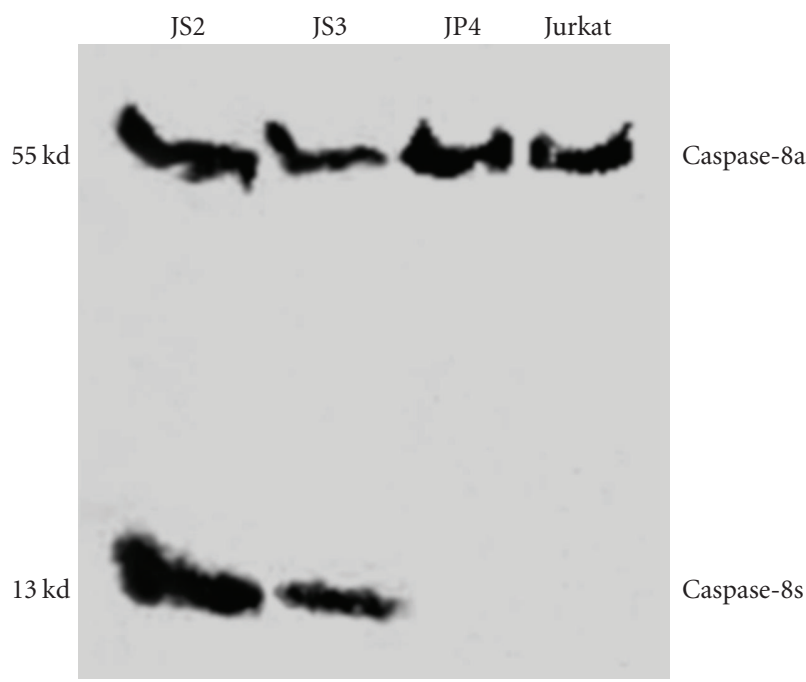

FIGURE 5: Western bolt identified the protein expression of caspase$8 \mathrm{~s}$ in caspase-8s-transfected cell clones: $50 \mu \mathrm{g}$ of total protein from lysates of empty vector (JP4 clone) or caspase-8s-transfected (JS2 clone, JS3 clone) Jurkat cells and wild-type Jurkat cells were subjected to $10 \%$ SDS-PAGE and immunoblotted with the rabbit antiprocaspase-8 (C7849, Sigma). A $13 \mathrm{kd}$ caspase-8s protein was identified in JS2 and JS3. The $55 \mathrm{kd}$ bands were endogenous caspase- 8 protein.

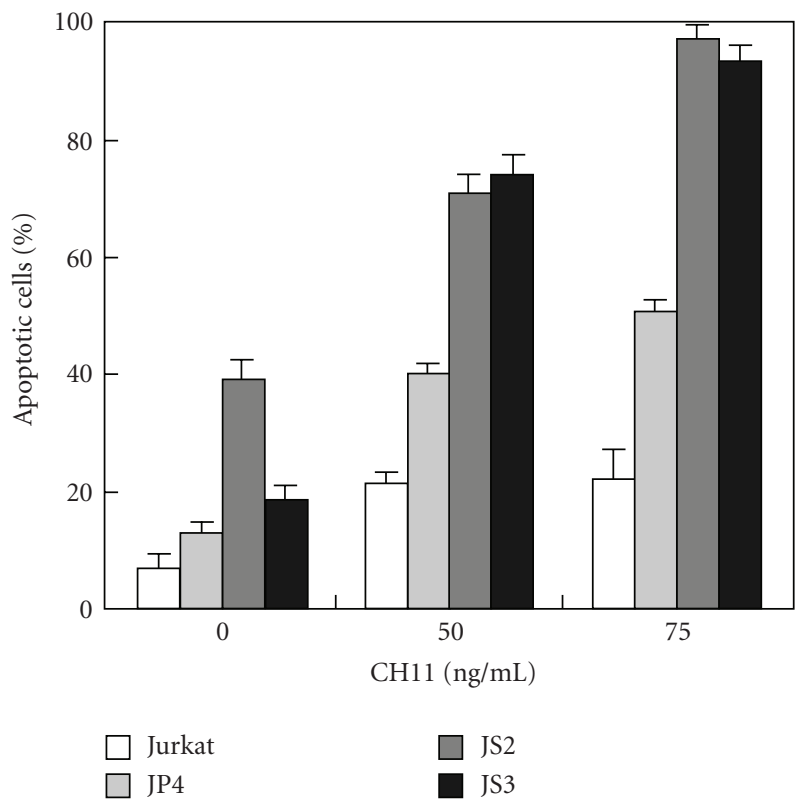

FIGURE 6: Caspase-8s promote cell apoptosis induced by Fas-agonistic antibody CH11: empty vector (JP4), caspase-8s-transfected (JS2, JS3) Jurkat cells and wild-type Jurkat cells were untreated or treated with $50 \mathrm{ng} / \mathrm{mL}$ and $75 \mathrm{ng} / \mathrm{mL}$ of $\mathrm{CH} 11$ for $24 \mathrm{~h}$. After stimulation, the cells were collected and resuspended in standard buffer solution to a concentration of $10^{6}$ cells $/ \mathrm{mL}$. Cells were incubated with in Annexin V-PE and 7-amino-actinomycin (7-AAD) for $15 \mathrm{~min}$ and analyzed on the FACScan. Early apoptotic cells were defined as those cells with Annexin V-PE staining in the absence of 7-AAD staining. Vector control transfected, caspase-8s-transfected, and wild type cells were analyzed in parallel. Apoptosis assays were run in triplicate revealing similar results (mean \pm SD).

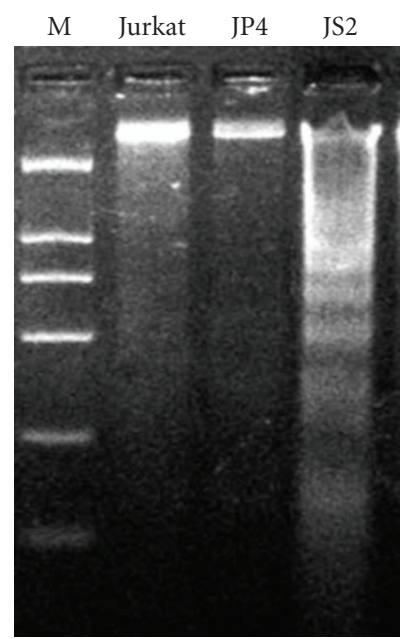

Figure 7: DNA fragmentation after exposure to Fas-agonistic antibody CH11: empty vector (JP4) or caspase-8s-transfected (JS2) Jurkat cells and wild-type Jurkat cells were treated with $75 \mathrm{ng} / \mathrm{mL}$ of $\mathrm{CH} 11$ for $24 \mathrm{~h}$ and genomic DNA extracted as described in "Materials and Methods" before electrophoresis in a 2.0\% agarose gel.

endogenous caspase-8. To evaluate the effect of caspase-8s expression on FAS-induced apoptosis, the annexin V-PE/7amino-actinomycin D (7-AAD) apoptosis detection kit was used; JS2 and JS3 cells displayed higher apoptosis rates when compared to wild type Jurkat and JP4 cells treated with serial dilutions of CH11 (Figure 6). DNA fragment formation assay which is the characteristic for apoptosis also indicated DNA degradation of JS2 cells treated with $\mathrm{CH} 11$ comparing to wild type Jurkat cell, and JP4 cells (Figure 7). In addition, the methyl thiazoleterazolium (MTT) assays showed that the mean growth inhibitory rate of $\mathrm{CH} 11$ for JS2 cells was higher than that of wild type Jurkat cells and JP4 cells. There was no significant difference between wild type Jurkat cells and JP4 cells (Figure 8). These data suggested that caspase$8 \mathrm{~s}$ itself might not exhibit proapoptotic activity; however, overexpressed caspase-8s promoted cell apoptosis and DNA fragmentation formation induced by death receptor agonists (anti-Fas antibodies).

In fact, some other DED-containing proteins are found to regulate apoptotic signal pathways. c-FLIP and PEA15 (phosphoprotein enriched in astrocytes $15-\mathrm{Kda}$ ) inhibit apoptosis by blocking recruitment of the caspases into aggregates [25, 32]. FADD, caspase-8d, and artificially constructed caspase- 8 prodomains induce apoptosis when highly overexpressed [3]. The function of DED proteins in apoptosis has been extensively reviewed elsewhere [33]. In our study, caspase-8s might be involved in the progression of apoptosis pathway, but the definite mechanism still needs to be confirmed. In Fas signaling apoptosis, two pathways are involved, in which the activation of caspase- 8 is different. In type I pathway, induction of apoptosis was accompanied by activation of large amounts of caspase- 8 by DISC, whereas in type II pathway, DISC formation was strongly reduced and activation of caspase- 8 and caspase- 3 occurred following 


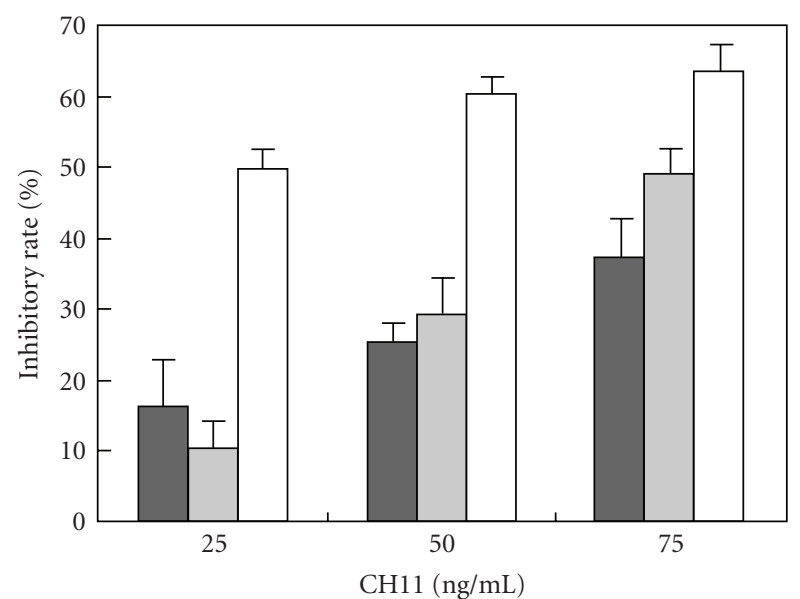

$\square$ Jurkat
$\square$ JP4
$\square$ JS2

FIGURE 8: MTT assays Empty vector (JP4) or caspase-8s-transfected (JS2) Jurkat cells and wild-type Jurkat cells were untreated or treated with $25 \mathrm{ng} / \mathrm{mL}, 50 \mathrm{ng} / \mathrm{mL}$, and $75 \mathrm{ng} / \mathrm{mL}$ of CH11 for $24 \mathrm{~h}$. The wells containing nonexposed cells were defined as having $100 \%$ viability. The data are from 3 independent MTT experiments and represent as mean $\pm \mathrm{SD}$.

the loss of mitochondrial transmembrane potential; however, in type II but not type I pathway, overexpression of Bcl-2 or Bcl-xL blocked caspase- 8 and caspase- 3 activation as well as apoptosis $[34,35]$. Gonzalvez et al. showed that cardiolipin is required for apoptosis in the type II mitochondria dependent response to Fas stimulation. Cardiolipin provides an anchor and activating platform for caspase8 translocation to, and embedding in, the mitochondrial membrane, where it oligomerizes and is further activated [36]; whether caspase-8s binds to mitochondria and induces apoptosis. Since Jurkat cells are of type II cells, to further explore the effect of caspase-8s expression on apoptosis pathway, DiOC6/PI test was used to monitor the mitochondrial membrane potential. $\mathrm{CH} 11(50 \mathrm{ng} / \mathrm{mL})$ induced a decrease of DiOC6 staining about $79 \%$ in caspase-8s-transfected Jurkat cells JS2, but the mitochondrial membrane potentials of empty vector-transfected Jurkat cells JP4 and wild-type Jurkat cells were not significantly influenced by $\mathrm{CH} 11$ (Figure 9). This indicates that caspase-8s overexpression may induce apoptosis in mitochondria dependent way.

In the study, to exclude the effect of lentiviral transduction of Jurkat cells on the expression of FAS antigen, RT-PCR and flow cytometry were performed to detect the expression of Fas mRNA and protein in empty vector or caspase-8stransfected Jurkat cells and wild-type Jurkat cells. The results indicated that there was no statistically significant difference in Fas expression between wild Jurkat cells and lentiviral transfected Jurkat cells (Figures 10 and 11). Balcaitis et al. [37] had examined the effect of lentiviral transduction of microglial cells on the expression of cell surface markers by

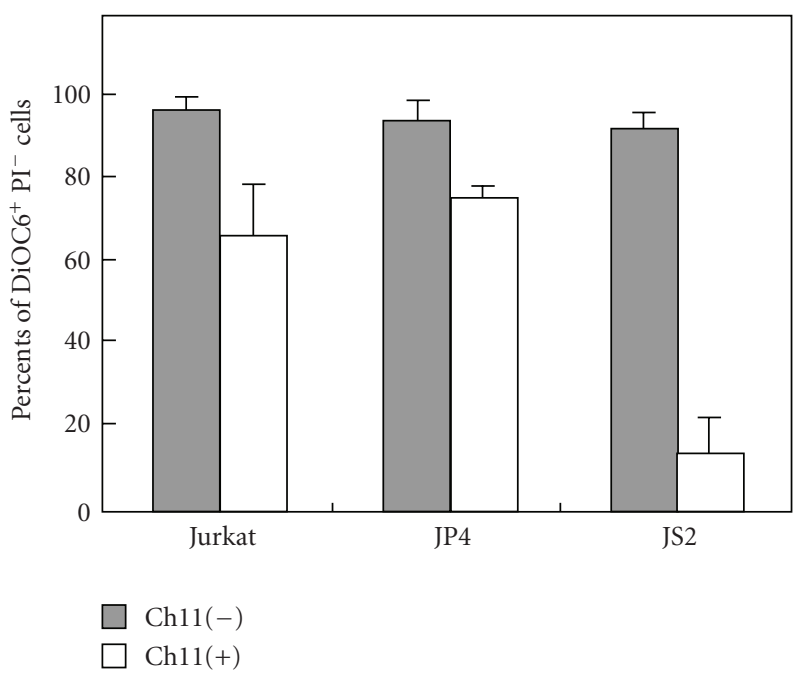

FIGURE 9: Mitochondrial membrane depolarization was assessed by the loss of DiOC6 staining of the mitochondria: flow cytometric analysis of the effect of anti-Fas mAb (CH11) treatment on mitochondrial transmembrane potential of empty vector (JP4) or caspase-8s-transfected Jurkat cells (JS2) and wild-type Jurkat cells. Cells untreated and treated with $50 \mathrm{ng} / \mathrm{mL} \mathrm{CH11} \mathrm{for} 24 \mathrm{~h}$ were double stained with DiOC6 and PI. Data shown are representative of three independent experiments.
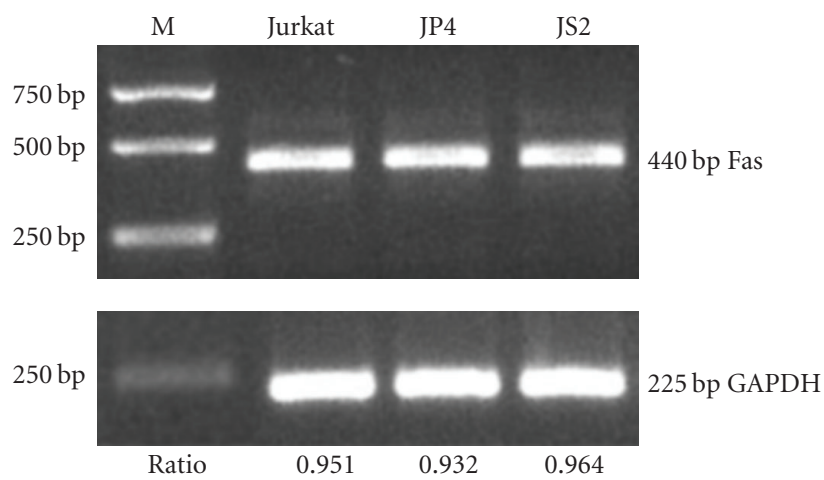

FIGURE 10: Expression of Fas mRNA in empty vector or caspase8s-transfected Jurkat cells and wild-type Jurkat cells was detected by semiquantitative RT-PCR: the PCR products were resolved on $1.5 \%$ agarose gel and visualized by ethidium bromide staining. The efficacy of RT-PCR was verified by detection of the human GAPDH mRNA. $\mathrm{R}=$ densitometrical units of Fas/densitometrical units of GAPDH.

flow cytometry including FAS antigen; no difference of Fas antigen expression was observed.

\section{Conclusion}

In conclusion, a novel isoform of caspase-8, named caspase8 s, was identified in human leukemia patients and healthy individuals. The transcript encodes the first and part of the second stretches of DED but lacks the proteolytic domain. Caspase-8s promoted the apoptosis induced by anti-Fas antibodies. Caspase-8s may participate in the regulation of 


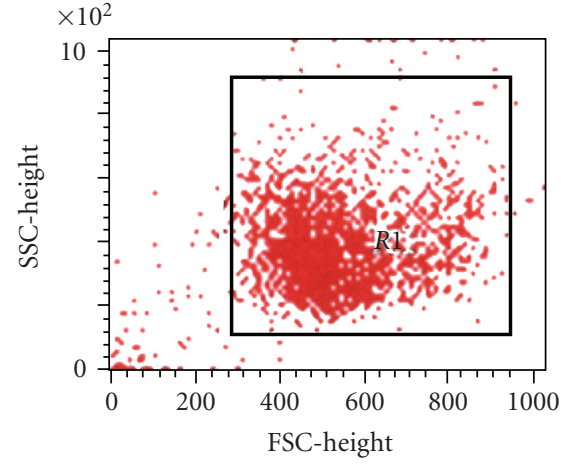

(a)

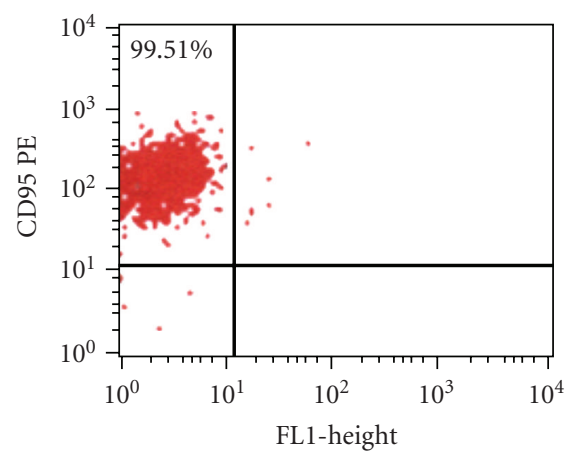

(d)

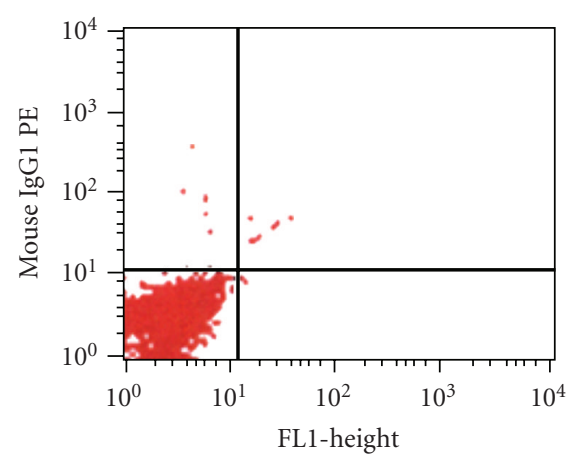

(b)

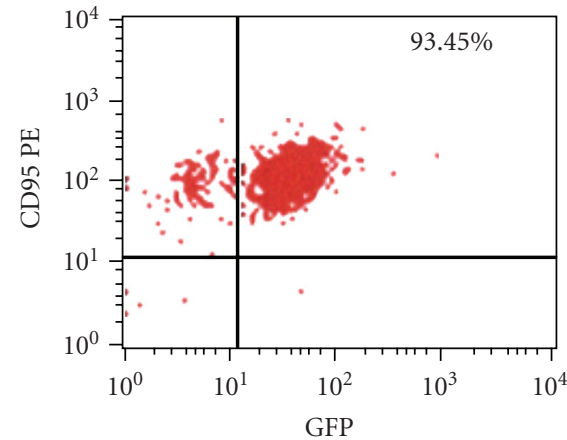

(e)

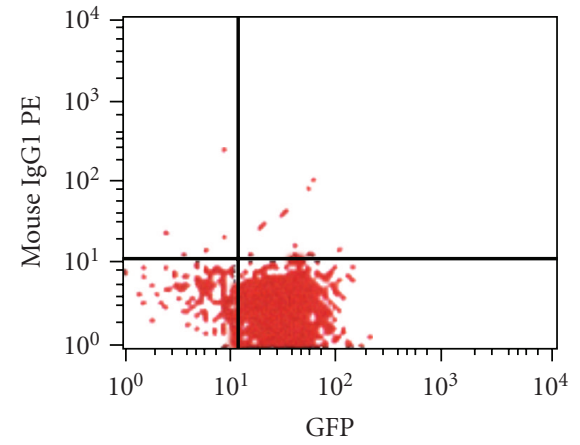

(c)

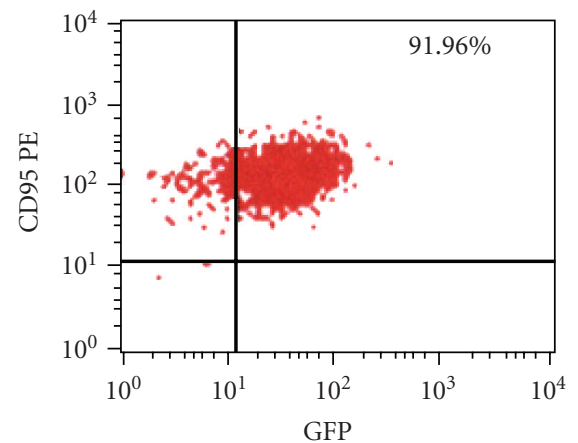

(f)

Figure 11: Expression of Fas Antigen in empty vector or caspase-8s-transfected Jurkat cells and wild-type Jurkat cells was analyzed by flow cytometry. (a) Analysed Jurkat cells were gated according to their size (FSC) and granularity (SSC). (b) Jurkat cell incubated with PE conjugated mouse IgG1 as isotype negative control. (c) JP4 (GFP positive cells) incubated with PE conjugated mouse IgG1 as isotype negative control. (d-f) Expression of Fas antigen in wild-type Jurkat cells, empty vector and, caspase-8s-transfected Jurkat cells. Numbers indicate the percentage of cells in the quadrant. Data shown are representative of three independent experiments.

caspase cascade. In addition, we also found that the first DED was an important structure mediating combination between caspase-8 and FADD. In AL patients, imbalanced expression of caspase-8s is being studied in our laboratory. Further research is needed to elucidate the function of caspase- $8 \mathrm{~s}$ in apoptosis.

\section{Acknowledgments}

The authors are grateful to kind assistance from the technicians in Flow Cytometry Core and Instrument Center, Institute of Hematology and Blood Diseases Hospital, Chinese Academy of Medical Sciences and Peking Union Medical College. This work was supported by Major State Basic Research Program of China (Grant no. 2006CB910406), National Natural Science Fund (30871096) of China, and Key Projects in Science \& Technology Pillar Program of Tianjin (07ZCKFSH00900).

\section{References}

[1] N. A. Thornberry and Y. Lazebnik, "Caspases: enemies within,” Science, vol. 281, no. 5381, pp. 1312-1316, 1998.

[2] K. M. Boatright, M. Renatus, F. L. Scott, et al., "A unified model for apical caspase activation," Molecular Cell, vol. 11, no. 2, pp. 529-541, 2003.
[3] A. M. Chinnalyan, K. O'Rourke, M. Tewari, and V. M. Dixit, "FADD, a novel death domain-containing protein, interacts with the death domain of Fas and initiates apoptosis," Cell, vol. 81, no. 4, pp. 505-512, 1995.

[4] M. P. Boldin, T. M. Goncharov, Y. V. Goltsev, and D. Wallach, "Involvement of MACH, a novel MORT1/FADD-interacting protease, in Fas/APO-1-and TNF receptor-induced cell death," Cell, vol. 85, no. 6, pp. 803-815, 1996.

[5] M. Muzio, A. M. Chinnaiyan, F. C. Kischkel, et al., "FLICE, a novel FADD-homologous ICE/CED-3-like protease, is recruited to the CD95 (Fas/APO-1) death-inducing signaling complex," Cell, vol. 85, no. 6, pp. 817-827, 1996.

[6] H. Li, H. Zhu, C.-J. Xu, and J. Yuan, "Cleavage of BID by caspase 8 mediates the mitochondrial damage in the Fas pathway of apoptosis," Cell, vol. 94, no. 4, pp. 491-501, 1998.

[7] H. R. Stennicke, J. M. Jurgensmeier, H. Shin, et al., "Procaspase-3 is a major physiologic target of caspase-8," The Journal of Biological Chemistry, vol. 273, no. 42, pp. 2708427090, 1998.

[8] U. Fischer, C. Stroh, and K. Schulze-Osthoff, "Unique and overlapping substrate specificities of caspase- 8 and caspase10," Oncogene, vol. 25, no. 1, pp. 152-159, 2006.

[9] M. Muzio, B. R. Stockwell, H. R. Stennicke, G. S. Salvesen, and V. M. Dixit, "An induced proximity model for caspase- 8 activation," The Journal of Biological Chemistry, vol. 273, no. 5, pp. 2926-2930, 1998.

[10] T. Fernandes-Alnemri, R. C. Armstrong, J. Krebs, et al., "In vitro activation of CPP32 and Mch3 by Mch4, a novel 
human apoptotic cysteine protease containing two FADD-like domains," Proceedings of the National Academy of Sciences of the United States of America, vol. 93, no. 15, pp. 7464-7469, 1996.

[11] T. Mosmann, "Rapid colorimetric assay for cellular growth and survival: application to proliferation and cytotoxicity assays," Journal of Immunological Methods, vol. 65, no. 1-2, pp. 55-63, 1983.

[12] W.-H. Liu and L.-S. Chang, "Arachidonic acid induces Fas and FasL upregulation in human leukemia U937 cells via $\mathrm{Ca}^{2+} /$ ROS-mediated suppression of ERK/c-Fos pathway and activation of p38 MAPK/ATF-2 pathway," Toxicology Letters, vol. 191, no. 2-3, pp. 140-148, 2009.

[13] J. Grenet, T. Teitz, T. Wei, V. Valentine, and V. J. Kidd, "Structure and chromosome localization of the human CASP8 gene," Gene, vol. 226, no. 2, pp. 225-232, 1999.

[14] H. S. Kim, J. W. Lee, Y. H. Soung, et al., "Inactivating mutations of caspase- 8 gene in colorectal carcinomas," Gastroenterology, vol. 125, no. 3, pp. 708-715, 2003.

[15] Y. H. Soung, J. W. Lee, S. Y. Kim, et al., "Caspase-8 gene is inactivated by somatic mutations in gastric carcinomas," Cancer Research, vol. 65, no. 3, pp. 815-821, 2005.

[16] Y. H. Soung, J. W. Lee, S. Y. Kim, et al., "Caspase- 8 gene is frequently inactivated by the frameshift somatic mutation 1225_1226delTG in hepatocellular carcinomas," Oncogene, vol. 24, no. 1, pp. 141-147, 2005.

[17] B. Liu, D. Peng, Y. Lu, W. Jin, and Z. Fan, "A novel single amino acid deletion caspase- 8 mutant in cancer cells that lost proapoptotic activity," The Journal of Biological Chemistry, vol. 277, no. 33, pp. 30159-30164, 2002.

[18] N. Shivapurkar, S. Toyooka, M. T. Eby, et al., "Differential inactivation of caspase-8 in lung cancers," Cancer Biology \& Therapy, vol. 1, no. 1, pp. 65-69, 2002.

[19] T. Teitz, J. M. Lahti, and V. J. Kidd, "Aggressive childhood neuroblastomas do not express caspase-8: an important component of programmed cell death," Journal of Molecular Medicine, vol. 79, no. 8, pp. 428-436, 2001.

[20] T. J. Zuzak, D. F. Steinhoff, L. N. Sutton, P. C. Phillips, A. Eggert, and M. A. Grotzer, "Loss of caspase- 8 mRNA expression is common in childhood primitive neuroectodermal brain tumour/medulloblastoma," European Journal of Cancer, vol. 38, no. 1, pp. 83-91, 2002.

[21] K. Harada, S. Toyooka, N. Shivapurkar, et al., "Deregulation of caspase 8 and 10 expression in pediatric tumors and cell lines," Cancer Research, vol. 62, no. 20, pp. 5897-5901, 2002.

[22] C. Scaffidi, J. P. Medema, P. H. Krammer, and M. E. Peter, "FLICE is predominantly expressed as two functionally active isoforms, caspase-8/a and caspase-8/b," The Journal of Biological Chemistry, vol. 272, no. 43, pp. 26953-26958, 1997.

[23] D. Himeji, T. Horiuchi, H. Tsukamoto, K. Hayashi, T. Watanabe, and M. Harada, "Characterization of caspase-8L: a novel isoform of caspase- 8 that behaves as an inhibitor of the caspase cascade,” Blood, vol. 99, no. 11, pp. 4070-4078, 2002.

[24] R. R. Kisenge, H. Toyoda, J. Kang, et al., "Expression of shortform caspase 8 correlates with decreased sensitivity to Fasmediated apoptosis in neuroblastoma cells," Cancer Science, vol. 94, no. 7, pp. 598-605, 2003.

[25] C. Scaffidi, I. Schmitz, P. H. Krammer, and M. E. Peter, "The role of c-FLIP in modulation of CD95-induced apoptosis," The Journal of Biological Chemistry, vol. 274, no. 3, pp. 1541-1548, 1999.

[26] H.-B. Shu, D. R. Halpin, and D. V. Goeddel, "Casper is a FADD- and caspase-related inducer of apoptosis," Immunity, vol. 6, no. 6, pp. 751-763, 1997.
[27] S. M. Srinivasula, M. Ahmad, S. Ottilie, et al., "FLAME1, a novel FADD-like anti-apoptotic molecule that regulates Fas/TNFR1-induced apoptosis," The Journal of Biological Chemistry, vol. 272, no. 30, pp. 18542-18545, 1997.

[28] Y. V. Goltsev, A. V. Kovalenko, E. Arnold, E. E. Varfolomeev, V. M. Brodianskii, and D. Wallach, "CASH, a novel caspase homologue with death effector domains," The Journal of Biological Chemistry, vol. 272, no. 32, pp. 19641-19644, 1997.

[29] D. K. M. Han, P. M. Chaudhary, M. E. Wright, et al., "MRIT, a novel death-effector domain-containing protein, interacts with caspases and BclXL and initiates cell death," Proceedings of the National Academy of Sciences of the United States of America, vol. 94, no. 21, pp. 11333-11338, 1997.

[30] S.-I. Tsukumo and S. Yonehara, "Requirement of cooperative functions of two repeated death effector domains in caspase8 and in MC159 for induction and inhibition of apoptosis, respectively," Genes to Cells, vol. 4, no. 9, pp. 541-549, 1999.

[31] P. E. Carrington, C. Sandu, Y. Wei, et al., "The structure of FADD and its mode of interaction with procaspase-8," Molecular Cell, vol. 22, no. 5, pp. 599-610, 2006.

[32] D. Kitsberg, E. Formstecher, M. Fauquet, et al., "Knockout of the neural death effector domain protein PEA-15 demonstrates that its expression protects astrocytes from TNF $\alpha$-induced apoptosis," The Journal of Neuroscience, vol. 19, no. 19, pp. 8244-8251, 1999.

[33] M. G. Valmiki and J. W. Ramos, "Death effector domaincontaining proteins," Cellular and Molecular Life Sciences, vol. 66, no. 5, pp. 814-830, 2009.

[34] B. C. Barnhart, E. C. Alappat, and M. E. Peter, "The CD95 Type I/Type II model," Seminars in Immunology, vol. 15, no. 3 , pp. 185-193, 2003.

[35] C. Scaffidi, S. Fulda, A. Srinivasan, et al., "Two CD95 (APO1/Fas) signaling pathways," The EMBO Journal, vol. 17, no. 6, pp. 1675-1687, 1998.

[36] F. Gonzalvez, Z. T. Schug, R. H. Houtkooper, et al., "Cardiolipin provides an essential activating platform for caspase-8 on mitochondria," Journal of Cell Biology, vol. 183, no. 4, pp. 681-696, 2008.

[37] S. Balcaitis, J. R. Weinstein, S. Li, J. S. Chamberlain, and T. Moller, "Lentiviral transduction of microglial cells," GLIA, vol. 50, no. 1, pp. 48-55, 2005. 

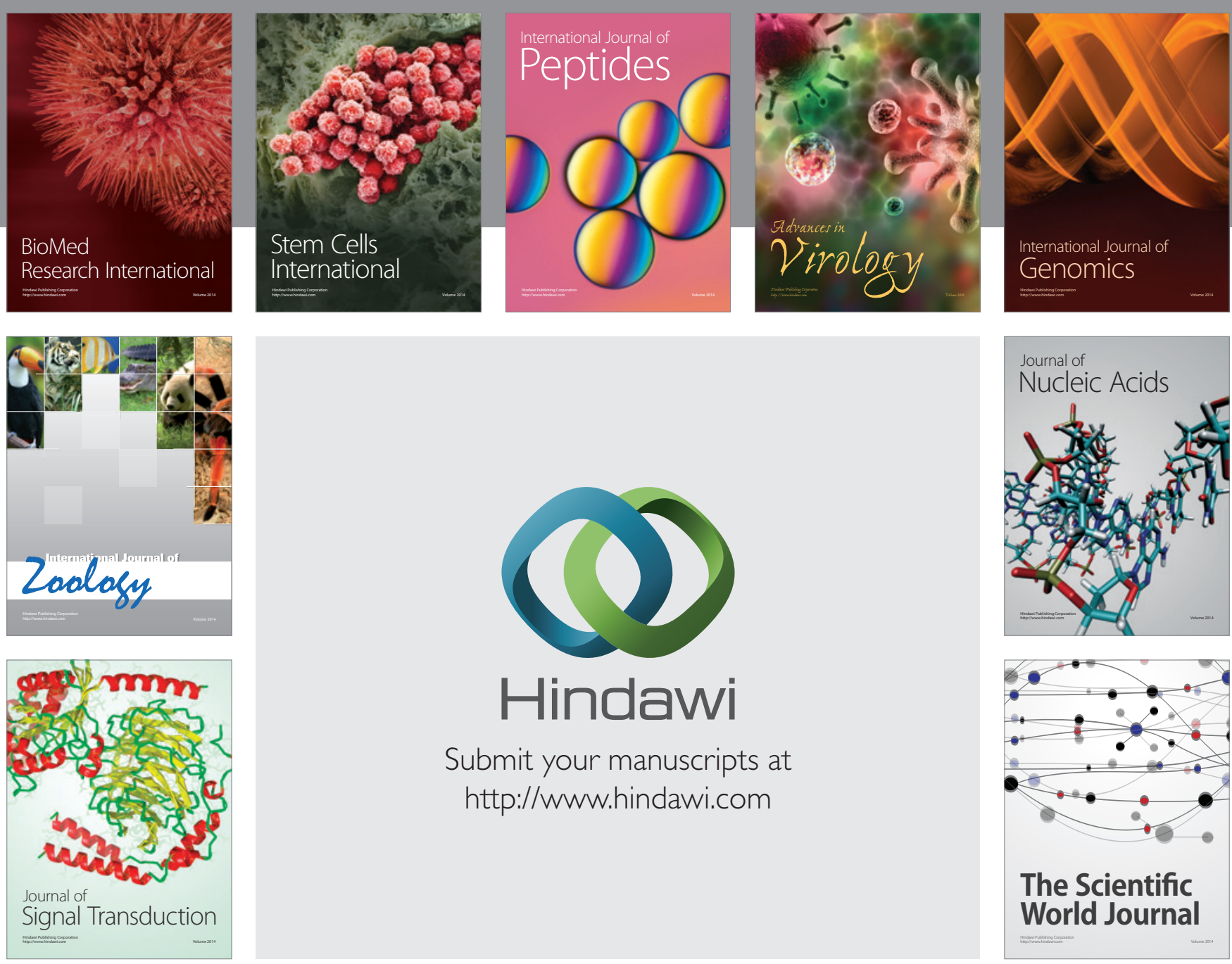

Submit your manuscripts at

http://www.hindawi.com
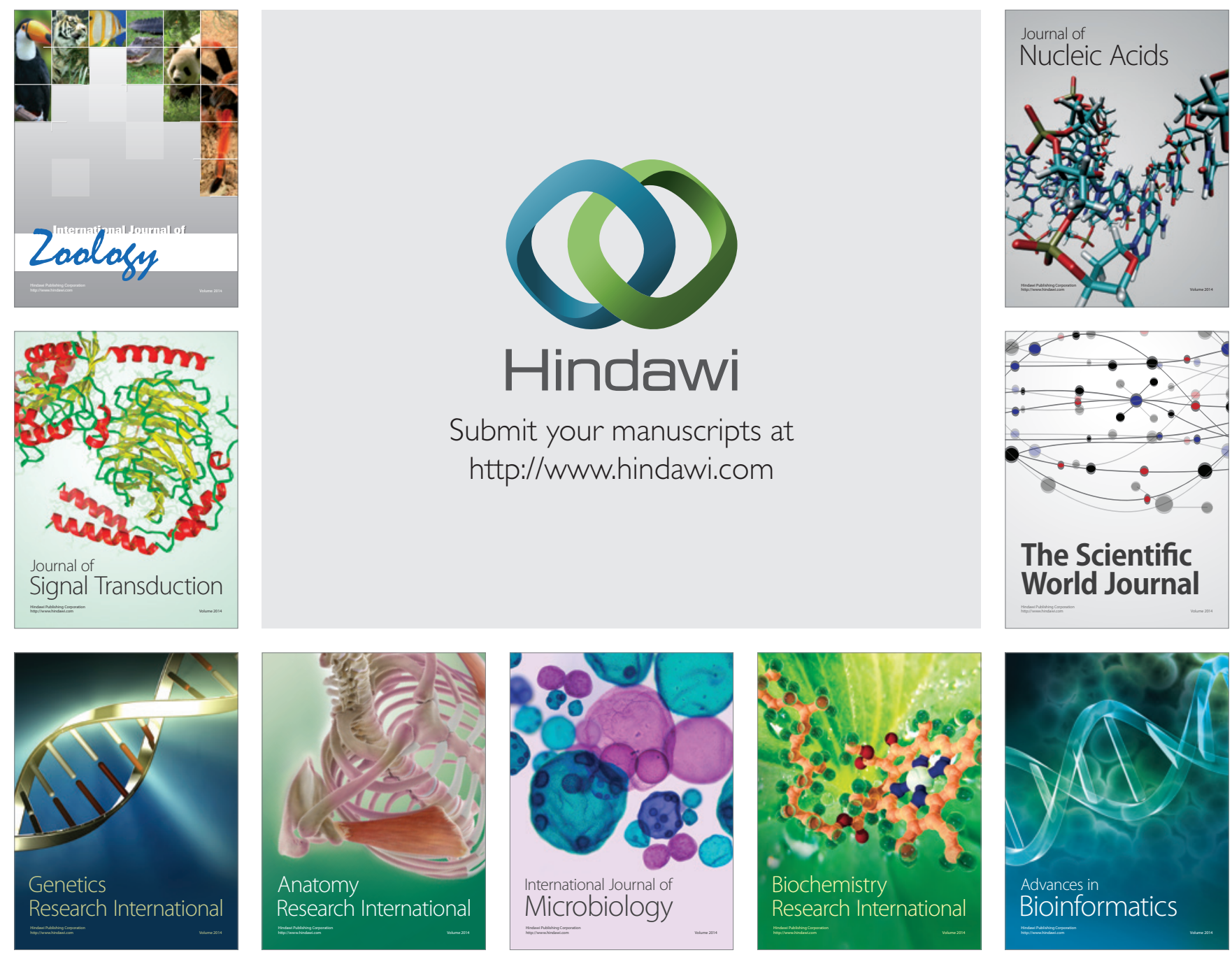

The Scientific World Journal
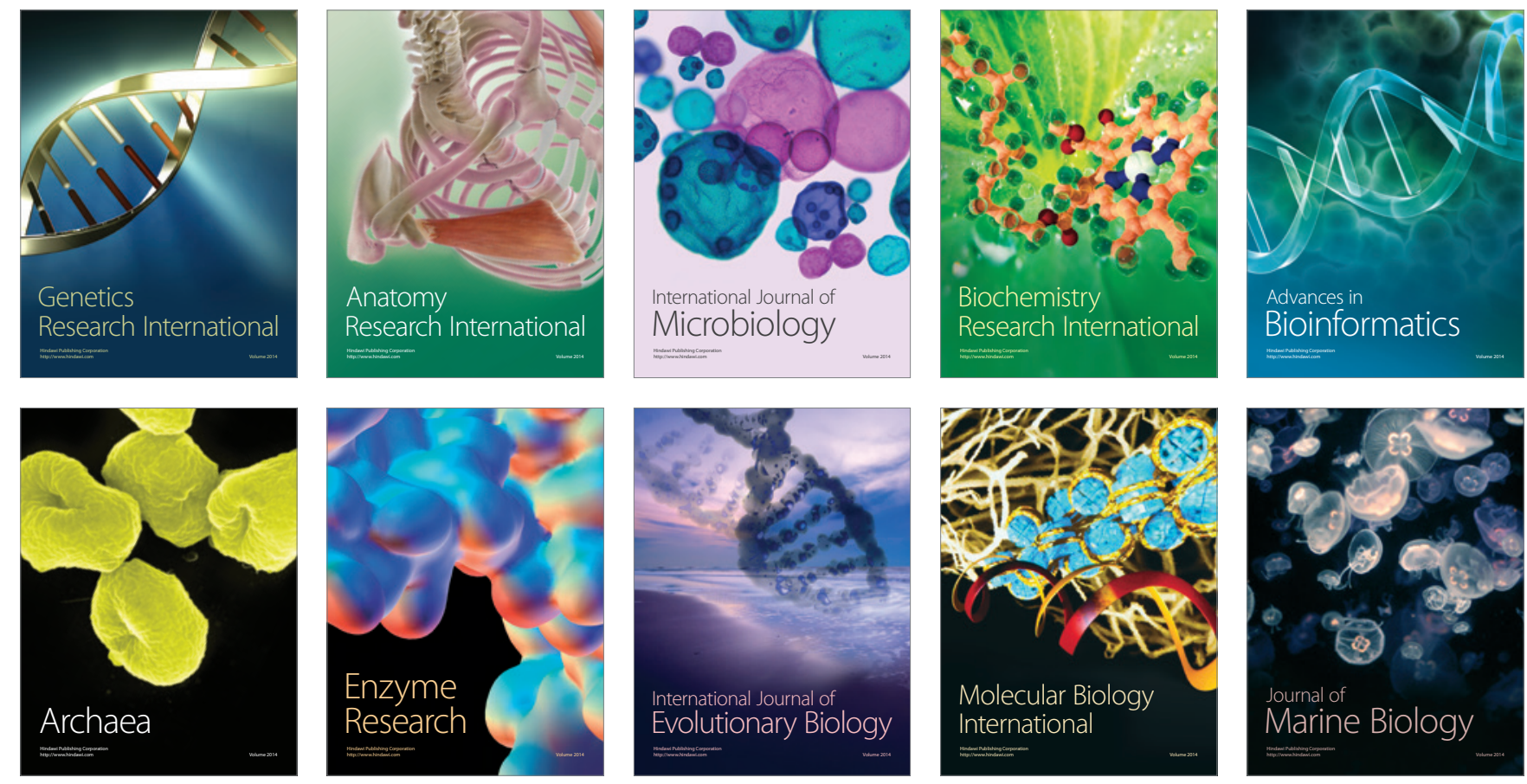